This essay is part of IJARBM's special issue

"Contemporary Applied Business Research

in Light of Standard Academic Literature".

\title{
The Shared Information System: a Relevant Solution for Knowledge Sharing and Decision Making Process
}

\author{
Ethan Aboiron \\ ethan.aboiron@neofaculty.org \\ Neofaculty Lab, Barcelona, Spain \\ Jeremie Aboiron \\ aboiron@neofaculty.org \\ Neofaculty Lab, Barcelona, Spain \\ https://doi.org/10.51137/ijarbm.2022.3.1.6
}

\begin{abstract}
It seems obvious to us that the knowledge management approach is a factor in innovation and the creation of sustainable competitive advantages. In a context of uncertainty, companies strengthen their core skills and competencies in order to enable the organization to implement underlying experiments and bring out innovations. Building a learning organization also means having a culture of challenge and exchange. This means being able to question established systems, renew experiences and constantly improve the knowledge acquired. Building a learning organization also means fighting against the obstacles to this collective learning, such as: power struggles, personal experience as a given, competition between individuals or groups of individuals, the influence of stakeholders and access to information. The future of knowledge management and information systems lies in particular in the possibilities offered by technology. We are thinking in particular of Big Data and Artificial Intelligence.
\end{abstract}

Keywords - Information System, Digital Transformation, Knowledge Management, Big Data, Machine Learning, Innovation, Decision Making

\section{Introduction}

We will see that the individual does not have all the information necessary to make a decision and does not seek alternative solutions in order to obtain the most satisfactory result. We can see that the theory on this point is in line with what describes the actions of economic intelligence, namely: the collection of information, analysis and decision making. The objective is that at each level of the organization and at each stake, the decision making is based on an optimal analysis of the data in order to get rid of the uncertainty

The Shared Information System: a Relevant Solution for Knowledge Sharing and Decision Making Process 
factors that weigh on the organization. The concept of knowledge management really appeared under this name in the 1990s and can now rely on an important trend developed in particular by Nonaka and Takeuchi. We will see that other authors add that the management of activities and processes is intended to amplify the use and creation of knowledge in organizations according to two complementary and strongly intertwined purposes. It is in this context that all the information that is collected, processed, stored and used by the company constitutes an intangible asset that is essential to the company's development. Building a learning organization also means fighting against the obstacles to collective learning.

\section{The Information System: an Essential Decision- Making Tool}

Reix (2002) define an information system (IS) as "a set of social actors who memorize and transform representations via information technologies and operating modes (...) It is an organized set of resources: hardware, software, data, procedures, allowing the acquisition, processing, storage and communication of information in an organization".

Companies are ready to modify their operating mode and their production processes according to information systems. The factors favoring these changes are: access to technology; availability of services; processing costs; storage costs.

They are all criteria that push companies to invest more massively in their information systems. According to the US Department of Economy, investment in information systems, as a proportion of total investment in a company, has increased from 39\% in 1980 to $51 \%$ in 2007.

The investment in IS represents today more than half of the total investments. In Japan, companies are organized around their information system and priority is given to the collection and processing of information.

The information system has multiple impacts in terms of management and strategy. In particular, it allows: more sharing and access to information; better data analysis; better reactivity; more links with stakeholders; the IS is present throughout the value chain.

As one can imagine, we find IS throughout the value chain: in logistics, purchasing, production, sales, human resources, finance, etc.

Each actor, each director, manager or employee will have to make more or less strategic and operational decisions, depending on their hierarchical level.

To do so, they will need different information, but always as quickly as possible and of the highest quality in terms of validity and reliability.

The information system, just like business intelligence, is above all a matter of information culture as much as an investment. However, studies have shown that the amount of the investment is not correlated to the profitability of an information system.

The system responds to several determinants favoring its success: a favorable organizational culture; clear business processes; a strong IS

The Shared Information System: a Relevant Solution for Knowledge Sharing and Decision Making Process 
department; strong support from management; an incentive for managerial innovation; a cooperative work environment; a training system favoring managerial decision-making.

\section{"Give the Right Information to the Right Person} at the Right Time", Simon H. (1977)

\section{From Information to Decision Making}

At the beginning of the 20th century, researchers had agreed that the individual systematically made a rational decision. However, Simon (1979) challenged this position by introducing the notion of bounded rationality. Indeed, an individual makes a decision solely on the basis of the information he has in his possession at the time he makes his decision. At the same time, Simon demonstrates that the individual does not have all the information necessary to make a decision, and therefore does not seek alternative solutions in order to obtain the most satisfactory result. On the contrary, the individual will almost systematically choose the "least worst" solution. Hence the importance of having an information system that allows the collection and analysis of a large and growing amount of data. This will allow the decision-maker to have a maximum of information to optimize his decision making.

We will not address the issue of power struggles in the decision-making process as described in the work of Crozier (1977). However, it should be noted that the interplay of actors and power can be important in the decisionmaking process. The opposite phenomena can also occur, as illustrated by the Abilene paradox. Not wanting to contradict each other and raise discontent among stakeholders, the actors all end up going against their respective and collective interests.

The decision-making process is broken down into two parts: the identification of a problem and the resolution of the problem. Economic intelligence will therefore take place in the problem-solving phase. We can see that the theory on this point is in line with what describes business intelligence actions, namely: information gathering, analysis and decision making.

Simon (1979) describes the decision according to three distinct forms: the structured decision; semi-structured; and unstructured.

The form of the decision will join the type in a matrix constructed by Gory that we will describe a little later.

According to Anthony (1965), decision making varies according to the type of control on which the decision operates. It is broken down into three main typologies: Strategic (long-term); Management (tactical); and Operational (day-to-day).

Later, Gory (1971) created a matrix correlating the type of control and the form of decision. The objective is that at each level of the organization and at each issue, decision making is based on an optimal analysis of the data in order to get rid of the uncertainty factors that weigh on the organization. We

The Shared Information System: a Relevant Solution for Knowledge Sharing and Decision Making Process 
can therefore see that business intelligence processes are equivalent to decision-making processes. And above all, they act with the same objective: to enable decision making in an organization.

\section{Towards a Learning Organization}

The concept of knowledge management really appeared under this name in the 1990s and can be based today on an important trend developed in particular by Nonaka and Takeuchi. They divided knowledge into two forms: explicit knowledge and tacit knowledge.

To this, Grundstein (2000) adds that "the management of activities and processes is intended to amplify the use and creation of knowledge in organizations according to two complementary and strongly intertwined purposes: a patrimonial purpose and a purpose of sustainable innovation". It is in this context that all the information that is collected, processed, stored and used by the company constitutes an intangible asset that is essential to the company's development. Knowledge management is the first step in a dynamic of innovation and creation of a learning organization.

It should also be noted that knowledge creation systems are often not well protected, even though they are sometimes the source of strategic information for the company. The information generated by the systems in place is often more important than the company's manufacturing processes. Managers must therefore identify what is more important for their organization: the system or the information?

It seems obvious to us that the knowledge management approach is a factor of innovation and creation of sustainable competitive advantages. In a context of uncertainty, companies strengthen their core competencies in order to enable the organization to implement underlying experiments and bring out innovations. Building a learning organization also means having a culture of challenge and exchange. This means being able to question established systems, renew experiences and constantly improve the knowledge acquired. Building a learning organization also means fighting against the obstacles to this collective learning, such as: power struggles, personal experience as an asset, competition between individuals or groups of individuals, the influence of stakeholders and access to information.

Business intelligence is a collective process that acts with a single goal: the material and intellectual improvement of the organization as a whole. The common goal must be the priority and come before the often divergent individual interests. An organization is successful if, and only if, all its stakeholders act with the same goal and follow the same direction.

\section{$5 \quad$ Future Challenges}

The future of knowledge management and information systems lies in particular in the possibilities offered by technology. We are thinking in particular of Big Data and Artificial Intelligence.

The Shared Information System: a Relevant Solution for Knowledge Sharing and Decision Making Process 
Big Data is a challenge both in terms of knowledge management and economic intelligence, and from the point of view of implementing complex information systems. Preparing today to be able to collect, sort, and analyze tomorrow a quantity of data that will simply be colossal. That is to say, when we reach in 2025 a quantity of data of the order of Zetta-byte, that is to say a figure factor of 1021.

To ensure the collection and analysis of all this data, the human brain will no longer be sufficient. We will have to develop artificial intelligence capable of extracting the essence of all this data. In 2025, an individual will have nearly 5000 digital interactions per day with his environment. What will happen to organizations? It will simply be impossible for humans to aggregate and synthesize all this data to make quick decisions in an environment that will be even more agile and faster.

Business intelligence is now based on the ability of an individual or an organization to create collective intelligence.

To optimize the performance of a project, the levers of the organizations will remain organized around the triptych "Quality - Cost - Time". The good management of knowledge will remain a key factor of success in the future and the maintenance of organizations on their market. Indeed, the more information will be shared between the different stakeholders, the more it will remain updated and will allow everyone to have the necessary knowledge to solve complex situations and to make quick decisions.

\section{Conclusion}

Knowledge management and decision-making processes are highly dependent on digital transformations. Big Data is a challenge both in terms of knowledge management, business intelligence, and the implementation of complex information systems, and decision making. Indeed, the more organizations will be able to collect data on their market, their customers, etc., the more information they will have to make strategic decisions. Following the same logic, artificial intelligence and machine learning can significantly contribute to the analysis of increasingly important data, to offer faster answers from an operational and strategic point of view. Finally, the more information is shared between the different stakeholders, the more upto-date it will remain and the more everyone will have the knowledge needed to resolve complex situations and make quick decisions. This is how the organization will be able to remain learning and proactive on complex situations. 


\section{References}

Anthony, R. N. (1965). Planning and Control Systems: A Framework for Analysis [by]. Division of Research, Graduate School of Business Administration, Harvard University.

Crozier, M., \& Friedberg, E. (1977). L'acteur et le système.

Grundstein, M. (2000). From capitalizing on company knowledge to knowledge management. Knowledge management, classic and contemporary works, 12, 261-287.

Nonaka, I., \& Takeuchi, H. (1995). The knowledge-creating company: How Japanese companies create the dynamics of innovation. Oxford university press.

Reix R. et Rowe F. (2002), La recherche en systèmes d'information : de l'histoire au concept, éd F. Rowe, Faire de la recherche en systèmes d'information, Paris, Vuibert, 3-20.

Simon, H. A. (1979). Rational decision making in business organizations. The American economic review, 69(4), 493-513. https://www.jstor.org/stable/1808698 